\title{
Superelasticity in Polycrystalline Ni-Mn-Ga-Fe Microwires Fabricated by Melt-extraction
}

\author{
Yanfen Liu ${ }^{a, b}$, Xuexi Zhang ${ }^{a}$,Jingshun Liu', Dawei Xing, \\ Hongxian Shen ${ }^{a}$, Dongming Chen ${ }^{a}$, Jianfei Sun ${ }^{a *}$ \\ ${ }^{a}$ School of Materials Science and Engineering, Harbin Institute of Technology, Harbin 150001, China \\ ${ }^{b}$ Department of physics, Qiqihar University, Qiqihar 161006, China \\ 'School of Materials Science and Engineering, Inner Mongolia University of Technology, \\ Hohhot 010051, China
}

Received: September 9, 2014; Revised: May 12, 2015

\begin{abstract}
$\mathrm{Ni}_{48} \mathrm{Mn}_{26.4} \mathrm{Ga}_{19.7} \mathrm{Fe}_{5.9}$ microwires with grain size of 1-3 micron were successfully fabricated by melt-extraction. The superelastic effects in the microwires under various temperatures and loads were systematically demonstrated. The as-extracted microwires displayed partial superelasticity when attended at relatively high temperature. The critical stress for stress-induced martensite formation increases linearly with temperature and follows the Clausius-Clapeyron relationship. The temperature dependence of the as-extracted polycrystalline $\mathrm{Ni}_{48} \mathrm{Mn}_{26.4} \mathrm{Ga}_{19.7} \mathrm{Fe}_{5.9}$ microwires is $16.4 \mathrm{MPa} / \mathrm{K}$, which is higher compared with Ni-Mn-Ga single crystals. In addition, the as-extracted microwires display excellent shape memory behavior with the recovery strain and recovery ratio of $1.26 \%$ and $86 \%$, respectively, when the total strain reaches $1.47 \%$ at $310 \mathrm{~K}$.
\end{abstract}

Keywords: melt-extraction, $\mathrm{Ni}-\mathrm{Mn}$-Ga-Fe microwires, superelasticity, stress-induced martensite transformation

\section{Introduction}

Ni-Mn-Ga shape memory alloys (SMAs) (a type of Heusler alloys) show great potential in actuators and sensors due to their unique shape memory effect (SME), superelastic effect (SE) and high magnetic-field induced strains (MFIS). The superelasticity of SMAs arises from a reversible stress-induced martensitic transformation (SIMT) when loading or unloading at temperature regimes higher than martensite transformation temperature $\left(M_{\mathrm{s}}\right)^{1}$. Chernenko et al. reported the SE associated with the reversible SIMT ${ }^{2,3}$ in single crystalline $\mathrm{Ni}_{53.1} \mathrm{Mn}_{26.6} \mathrm{Ga}_{20.3}, \mathrm{Ni}_{51.2} \mathrm{Mn}_{31.1} \mathrm{Ga}_{17.7}$ and $\mathrm{Ni}_{49.4} \mathrm{Mn}_{27.7} \mathrm{Ga}_{22.9}$ alloys. The temperature dependence of the critical SIMT stress in Ni-Mn-Ga alloys follows a linear function, which can be deduced from both general thermodynamic expression and Landau theory. In polycrystalline $\mathrm{Ni}_{49.9} \mathrm{Mn}_{28.6} \mathrm{Ga}_{21.5}$ microwires, Qian et al. reported that SIMT stress increased linearly with the temperature and could be described by Clausius-Clapeyron relationship ${ }^{4}$.

The application of ternary $\mathrm{Ni}_{2} \mathrm{MnGa}$ SMAs is limited because of their low martensitic transformation temperature and high intergranular fracture tendency ${ }^{5}$. Thus, various options such as a fourth element doping and grain refinement have been used to improve the properties of Ni-Mn-Ga alloys. The brittleness of Ni-Mn-Ga alloy might be effectively improved by doping fourth transitional elements such as $\mathrm{Fe}^{6-7}, \mathrm{Co}^{7}, \mathrm{Cu}^{8-10}$ and $\mathrm{Y}^{11}$ or rare earth elements such as $\mathrm{Gd}^{12}$, $\mathrm{Dy}^{13}$ and $\mathrm{Tb}^{14}$. A recent report revealed that the brittleness and SME of Ni-Mn-Ga alloys were significantly improved through Fe-doping ${ }^{15}$. Moreover, grain refinement by rapid solidification technology is also an effective way to improve

*e-mail: jfsun_hit@263.net,jfsun@hit.edu.cn the SME and brittleness ${ }^{4,16,17}$ of Ni-Mn-Ga alloys. For example, Ni-Mn-Ga fibers with fine gains of 1-3 microns showed enhanced superelasticity and shape memory properties compared with the corresponding bulk alloys ${ }^{4}$.

In this work $\mathrm{Ni}_{48} \mathrm{Mn}_{26.4} \mathrm{Ga}_{19.7} \mathrm{Fe}_{5.9}$ microwires with diameters of $\sim 30-40 \mu \mathrm{m}$ and lengths of $\sim 10 \mathrm{~cm}$ were fabricated by melt-extraction method. The superelasticity of Fe-doped polycrystalline Ni-Mn-Ga microwires was systematically investigated.

\section{Experimental Details}

An ingot with a nominal composition of $\mathrm{Ni}_{48} \mathrm{Mn}_{26.4} \mathrm{Ga}_{19.7} \mathrm{Fe}_{5.9}$ (at. \%) was firstly prepared by arc-melting with pure $\mathrm{Ni}(99.99 \%), \mathrm{Mn}(99.99 \%), \mathrm{Ga}(99.99 \%)$, and $\mathrm{Fe}$ (99.99\%) elements under argon atmosphere. The ingot was then re-melted and extracted into microwires by a melt-extraction device ${ }^{4}$. The melt-extraction process was carried out using a copper wheel with a diameter of $320 \mathrm{~mm}$ and wheel-edge angle of $60^{\circ}$. During the melt-extraction, the wheel flange linear velocity and feeding rate of the molten material were fixed at $30 \mathrm{~m} / \mathrm{s}$ and $30 \mu \mathrm{m} / \mathrm{s}$, respectively.

The surface morphologies of the microwires were investigated on a scanning electron microscope (SEM-Helios Nanolab600i). Martensite transformation temperatures of the microwire were obtained with a Magnetic Property Measurement System (SQUID-VSM) made by Quantum Design. The temperatures dependence of magnetization $(M-T)$ curves were measured at a constant external magnetic field of $10 \mathrm{Oe}$ and heating/cooling rates of $5 \mathrm{~K} / \mathrm{min}$. 
The samples for the tensile tests have uniform diameters and gauge lengths of $2 \mathrm{~mm}$. The tensile stress-strain curves of the microwires were obtained using a dynamic mechanical analyzer (DMA Q800). The microwire was firstly heated to $353 \mathrm{~K}$ (slightly higher than $A_{\mathrm{f}}$ ) with a rate of $5 \mathrm{~K} / \mathrm{min}$ and kept at this temperature for $12 \mathrm{~min}$. Then the microwire was cooled to the test temperature (slightly higher than $M_{\mathrm{s}}$ ) and was subjected to a tensile loading-unloading cycle. A series of experimental methods for superelastic effect tests were formulated and shown in Table 1.

\section{Results and Discussion}

The morphology of an as-extracted microwire is shown in Figure 1a. The microwire has a plane surface (marked as A) and free circular surface (marked as B). The plane surface was formed by contact and solidification of the melt on the copper wheel. When the extracted melt filament left the copper wheel, the remaining melt grew from A to the free surface B (grew directions were marked with uni-directional arrows). The resulting cellular grain sizes on the free surface B are $\sim 1-3 \mu \mathrm{m}$.

A typical stress-strain (SS) curve during a cycle with loading/unloading processes and experimental parameters is shown in Figure 1b. During loading, the starting stress $\left(\sigma_{M s}\right)$ and finishing stress $\left(\sigma_{M f}\right)$ of the SIMT were denoted as A and $\mathrm{B}$ in Figure 1b. Upon unloading, the starting stress $\left(\sigma_{A s}\right)$ and finishing stress $\left(\sigma_{A f}\right)$ of the reverse austenite transformation were denoted as D and $\mathrm{E}$. The enclosed area of OABDEFO represents the hysteretic energy $(\Delta W)$ during a loading and unloading cycle. In Figure $1 \mathrm{~b}, \sigma_{u}, \varepsilon_{e}$ and $\varepsilon_{\text {res }}$ are the maximum strain, recoverable elastic strain and residual strain, respectively. The superelastic strain $\varepsilon_{S E}$ can be expressed by $\varepsilon_{S E}=\varepsilon_{u}-\varepsilon_{e}-\varepsilon_{\text {res }}$. OA, $\mathrm{AB}, \mathrm{BC}$ are respectively expressed as austenitic state, transformation state from austenite to martensite and martensitic state during loading process, and DBC, DE, EF are respectively expressed as martensitic state, transformation state from martensite to austenite and the austenitic state during the unloading process. The slopes of linear $\mathrm{OA}$ and $\mathrm{BC}$ are the deformation modulus of austenitic and martensitic state, respectively.

Figure 2 shows the temperatures dependence of magnetization $(M-T)$ curves for the $\mathrm{Ni}_{48} \mathrm{Mn}_{26.4} \mathrm{Ga}_{19.7} \mathrm{Fe}_{5.9}$ microwires at a constant external magnetic field of 10 Oe. The martensite starting $\left(M_{\mathrm{s}}\right)$ and finishing $\left(M_{\mathrm{f}}\right)$ temperatures were 305 and

Table 1. Superelastic tests of Ni-Mn-Ga-Fe microwires.

\begin{tabular}{|c|c|c|c|}
\hline Group & Loading method & $\begin{array}{c}\text { Loading/ } \\
\text { unloading } \\
\text { rate } \\
\text { (N/min) }\end{array}$ & $\begin{array}{c}\text { Test } \\
\text { temperature } \\
\text { (K) }\end{array}$ \\
\hline $1 \#$ & $\begin{array}{l}\text { Loaded to } 275 \mathrm{MPa} \text {, } \\
\text { unloaded and repeated } \\
4 \text { times }\end{array}$ & $0.04 / 0.075$ & 317 \\
\hline $2 \#$ & $\begin{array}{l}\text { Loaded to } 375 \mathrm{MPa} \text {, } \\
\text { unloaded and repeated } \\
3 \text { times }\end{array}$ & $0.04 / 0.075$ & $306,308,310,315$ \\
\hline $3 \#$ & $\begin{array}{l}\text { Loaded to } 250,313, \\
375 \mathrm{MPa} \text {, unloaded and } \\
\text { repeated } 3 \text { times }\end{array}$ & $0.04 / 0.075$ & 310 \\
\hline
\end{tabular}

$292 \mathrm{~K}$ during cooling process, respectively while the austenite starting $\left(A_{\mathrm{s}}\right)$ and finishing $\left(A_{\mathrm{f}}\right)$ temperatures were respectively 301 and $311.5 \mathrm{~K}$ during heating process. The thermal hysteresis $\left(\Delta T=A_{\mathrm{f}}-M_{\mathrm{s}}\right)$ was determined to be $\sim 6.5 \mathrm{~K}$.

Figure 3 displays the SS curves obtained based on the experimental methods Group 1\# (as shown in Table 1), every superelastic experiment tests is repeated four times. The SS curves overlapped during the four cycles which revealed a good stability of the superelastic cycles. As a result, the critical stresses for the phase transformation kept intact.

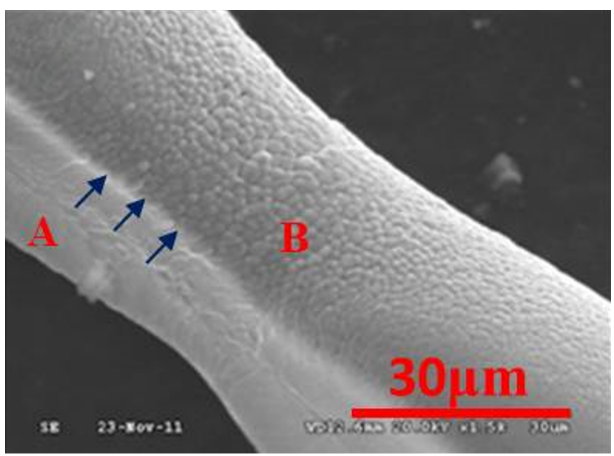

(a)

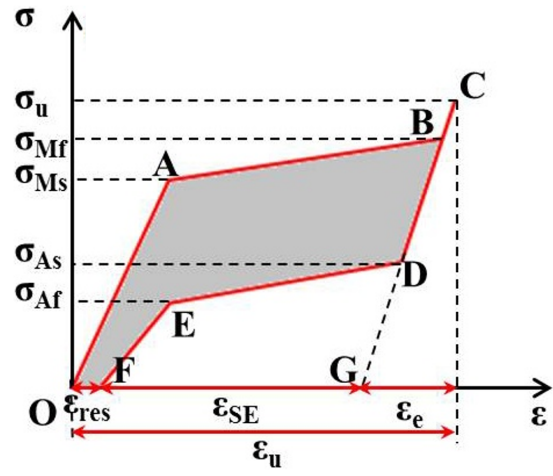

(b)

Figure 1. (a) SEM image of polycrystalline $\mathrm{Ni}_{48} \mathrm{Mn}_{26.4} \mathrm{Ga}_{19.7} \mathrm{Fe}_{5.9}$ fibers at room temperature. (b) Typical stress-strain curve.

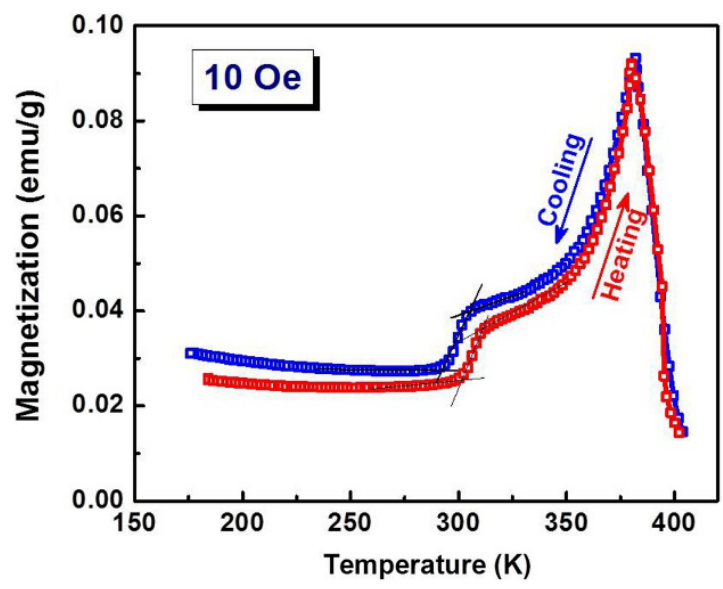

Figure 2. Magnetization versus temperature $(M-T)$ curves for $\mathrm{Ni}_{48} \mathrm{Mn}_{26.4} \mathrm{Ga}_{19.7} \mathrm{Fe}_{5.9}$ microwires. 
The SS curves of an as-extracted $\mathrm{Ni}_{48} \mathrm{Mn}_{26.4} \mathrm{Ga}_{19.7} \mathrm{Fe}_{5.9}$ microwire at various temperatures of $306,308,310$ and $315 \mathrm{~K}$ are plotted in Figure 4a (based on Group 2\# of experimental methods in Table 1). It is clearly shown that the microwire exhibited SE at these temperatures. The corresponding strains $\varepsilon_{u}, \varepsilon_{r e s}$ and $\varepsilon_{S E}$ as functions of temperatures are displayed in Figure $4 \mathrm{~b}$. The maximum strain achieved in the $\mathrm{Ni}_{48} \mathrm{Mn}_{26.4} \mathrm{Ga}_{19.7} \mathrm{Fe}_{5.9}$ microwire was $\sim 1.49 \%$, which is

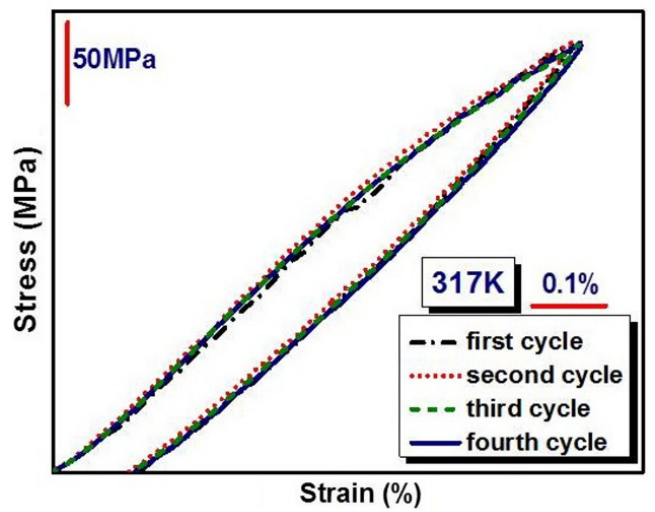

Figure 3. Tensile stress-strain curves under the same loading at austenite state $(317 \mathrm{~K})$ for as-extracted $\mathrm{Ni}_{48} \mathrm{Mn}_{26.4} \mathrm{Ga}_{19.7} \mathrm{Fe}_{5.9}$ microwires. much smaller than that in single-crystalline $\mathrm{Ni}_{54} \mathrm{Mn}_{25} \mathrm{Ga}_{21}$ alloys ( $\sim 10 \%$ for compressed state $\left.{ }^{15}\right)$, but close to that in polycrystalline Ni-Mn-Ga microwires $(\sim 2.7 \%)^{[4]}$. The maximum strain that can be achieved in polycrystalline Ni-Mn-Ga-Fe microwires is limited by the intergranular fracture during loading-unloading cycles. Figure $4 \mathrm{~b}$ shows that $\varepsilon_{u}$ and $\varepsilon_{r e s}$ decrease with the increase of temperatures. However, $\varepsilon_{S E} 1 *$ MERGEFORMAT increases with temperature until a maximum point $\left(\varepsilon_{S E}^{\max } *\right.$ MERGEFORMAT $\left.=0.54 \%\right)$ is reached. Such behavior has also been found in $\mathrm{Cu}-$ based $\mathrm{SMAs}^{18}$. The maximum recoverable ratio in $\mathrm{Ni}-\mathrm{Mn}-\mathrm{Ga}-\mathrm{Fe}$ microwires is $\sim 95.6 \%$ at $315 \mathrm{~K}$ as described in Figure $4 \mathrm{~b}$, which is much higher than Ni-Mn-Ga alloys $(\sim 63 \%)^{[15]}$ and comparable to $\mathrm{Ni}_{49.5} \mathrm{Mn}_{28.6} \mathrm{Ga}_{21.5}$ microwire ${ }^{4}$.

It can be seen from Figure $4 \mathrm{~b}$ that the strain recovery ratio increases with temperature and the residual strain decreases from $0.45 \%$ at $306 \mathrm{~K}$ to $0.05 \%$ at $315 \mathrm{~K}$. The higher recovery ratio at higher temperatures may be attributed to the higher density of elastic energy accumulated in the substrate during the process of SIMT ${ }^{1}$. The elastic energy and thermal energy act as the driving force for the strain recovery. Therefore, the residual strain decreases but recovery ratio increases with temperature.

Figure 4c shows plots of temperature dependence of deformation modulus. Contrary to the austenite, the reduced

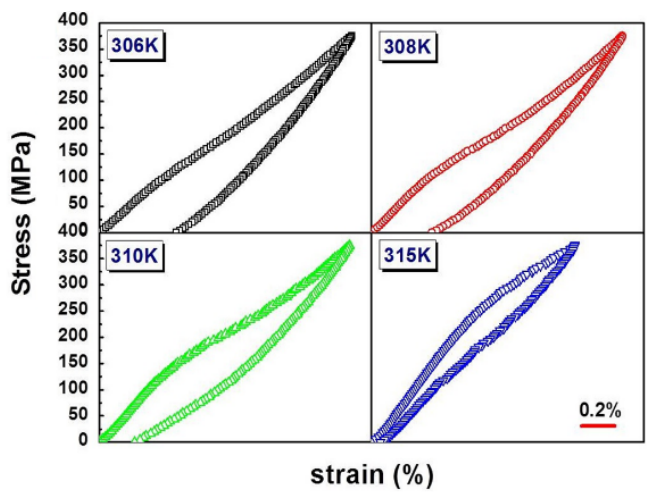

(a)

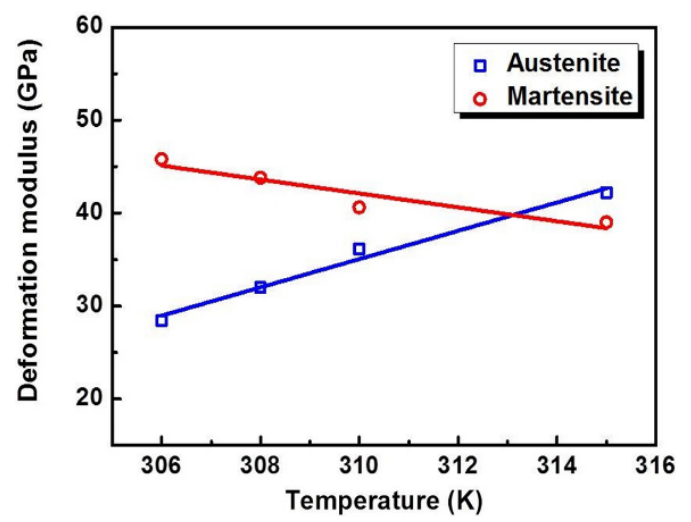

(c)

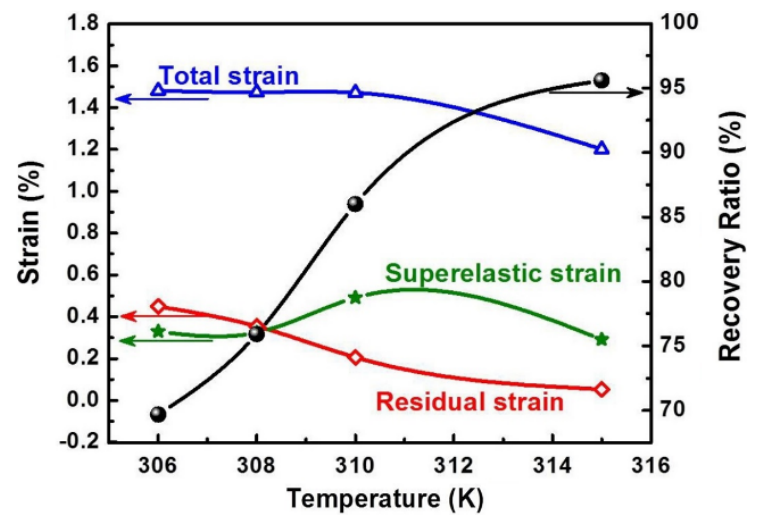

(b)

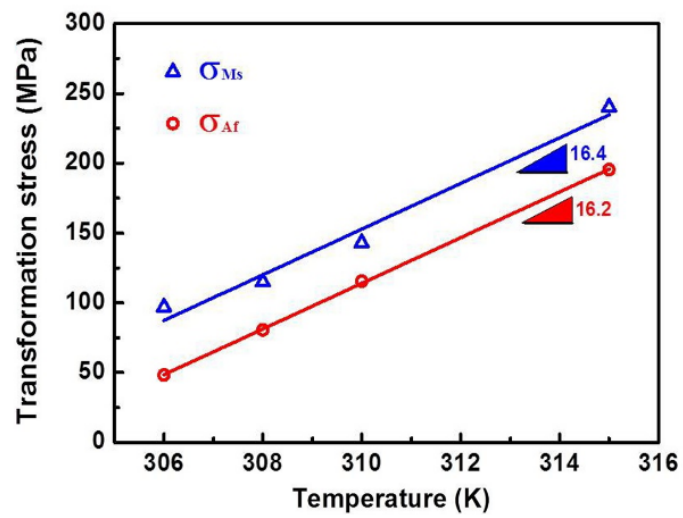

(d)

Figure 4. (a) Stress-strain curves at different temperatures in one cycle tensile test, (b) Temperature dependence of strain and recovery ratio, (c) Temperature dependent of deformation modulus and (d) Critical stress as a function of temperature of as-extracted $\mathrm{Ni}_{48} \mathrm{Mn}_{26.4} \mathrm{Ga}_{19.7} \mathrm{Fe}_{5.9}$ microwires. 


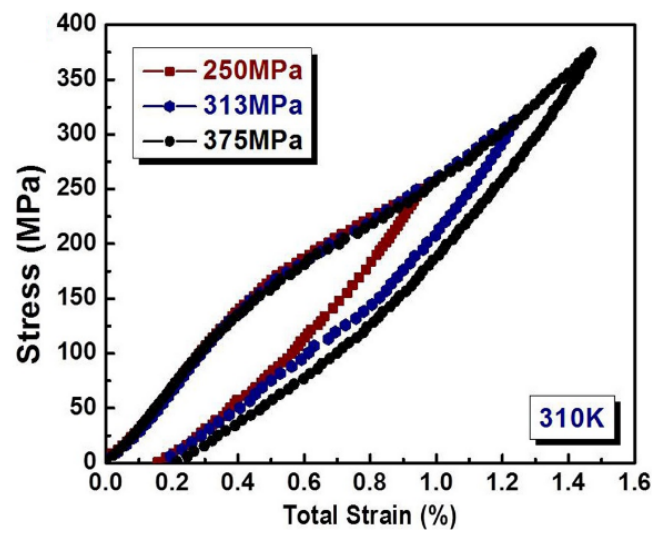

(a)

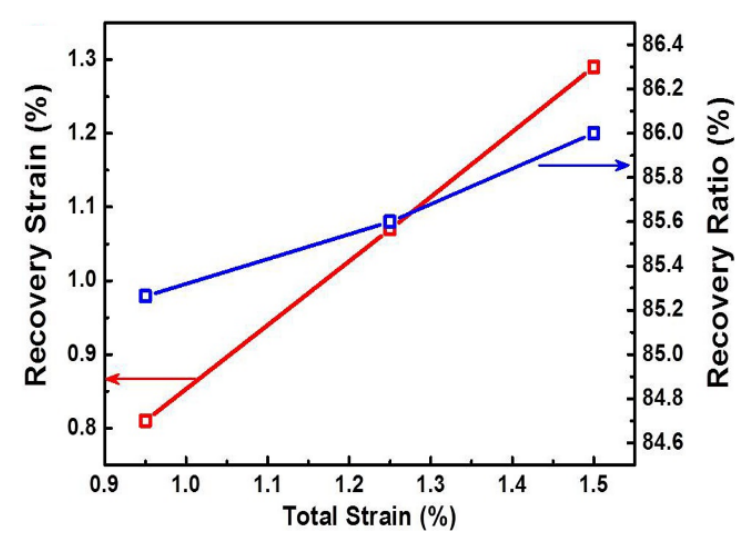

(b)

Figure 5. (a) Tensile stress-strain curves under different loadings at the same temperature of $310 \mathrm{~K}$, (b) recovery strain and recovery ratio vs total strain of as-extracted $\mathrm{Ni}_{48} \mathrm{Mn}_{26.4} \mathrm{Ga}_{19.7} \mathrm{Fe}_{5.9}$.

modulus of martensite with temperature can be found, which may be attributed to the softening of lattice vibration (provided by acoustic mode) during phase transformation. The reduced deformation modulus in the forward phase transformation correspond to the localized soft mode theory (LSMT) ${ }^{19}$.

Figure $4 \mathrm{~d}$ shows the temperature dependence of critical stress for SIMT in the as-extracted $\mathrm{Ni}_{48} \mathrm{Mn}_{26.4} \mathrm{Ga}_{19.7} \mathrm{Fe}_{5.9}$ microwires. From the $\sigma-\mathrm{T}$ curve, it is found that the critical stress exhibited a linear relationship with temperature. The slopes $(\mathrm{d} \sigma / \mathrm{d} T)$ of the $\sigma_{\mathrm{Ms}}-T$ and $\sigma_{\mathrm{Af}}-T$ curves were determined to be $\sim 16.4$ and $\sim 16.2 \mathrm{MPa} / \mathrm{K}$ from Figure $4 \mathrm{~d}$. The slopes in the present $\mathrm{Fe}$-doping Ni-Mn-Ga microwires are larger than that in Ni-Mn-Ga single crystals $(\sim 5.2 \mathrm{MPa} / \mathrm{K} \text { along }[110])^{3}$, which may be related to small grains (diameter $\sim 1-3 \mu \mathrm{m}$ ) created by rapid solidification during melt-extraction (see Figure 1a). In addition, the critical stress of $\mathrm{Ni}_{48} \mathrm{Mn}_{26.4} \mathrm{Ga}_{19.7} \mathrm{Fe}_{5.9}$ microwires showed higher temperature dependence than that in $\mathrm{Ni}_{49.5} \mathrm{Mn}_{28.6} \mathrm{Ga}_{21.5}$ microwires ${ }^{4}$ as well, which may be attributed to the solution strengthening effect of $\mathrm{Fe}$.

Figure 5a shows tensile stress-strain curves at $310 \mathrm{~K}$ under different loading-unloading cycles (the loadings were $250 \mathrm{MPa}, 313 \mathrm{MPa}$ and $375 \mathrm{MPa}$, respectively, based on the Group 3\# of experimental methods as shown in Table 1). These stress-strain curves overlapped during loading, displaying a well reproducibility during SIMT process. During unloading process, the slope of the curve decreased with increasing loads, revealing the reduced critical stress for austenite transformation with the increasing loads. Figure $5 \mathrm{~b}$ shows recovery strains and recovery ratios at different total strains. The strain recovery ratios are $85.2 \%, 85.6 \%$, $86 \%$ under loads of 250,313 and $375 \mathrm{MPa}$, corresponding to total strains of $0.951,1.24,1.47 \%$. The slightly increased recovery strain and recovery ratio with the increase of total strain are consistent with the increased stored elastic energy at higher loads.

\section{References}

1. Huang $X$ and Liu Y. Effect of annealing on the transformation behavior and superelasticity of NiTi shape memory alloy. Scripta Materialia. 2001; 45(2):153-160. http://dx.doi.org/10.1016/ S1359-6462(01)01005-3.

\section{Conclusions}

Fine grain polycrystalline $\mathrm{Ni}_{48} \mathrm{Mn}_{26.4} \mathrm{Ga}_{19.7} \mathrm{Fe}_{5.9}$ microwires were prepared by melt-extraction and their superelastic effects were conducted. The main conclusions are summarized as follows:

1) The martensite transformation starting temperature $\left(M_{\mathrm{s}}\right)$ in Fe-doped Ni-Mn-Ga microwires is $\sim 305 \mathrm{~K}$, which is close to the room temperature. The critical stress of SIMT increases linearly with increasing temperature, following the Clausius-Clapeyron relationship.

2) The temperature dependence of SE critical stress in $\mathrm{Ni}_{48} \mathrm{Mn}_{26.4} \mathrm{Ga}_{19.7} \mathrm{Fe}_{5.9}$ microwires is $16.4 \mathrm{MPa} / \mathrm{K}$, which is much higher than Ni-Mn-Ga bulk single-crystals and polycrystalline microwires.

3) The recovery strain increases with increasing temperature and the maximum strain recovery ratio is $\sim 95.6 \%$ at $315 \mathrm{~K}$.

\section{Acknowledgements}

This work was financially supported by National Natural Science Foundation of China (NSFC) under grant Nos. 51001038 and Ministry of Science and Technology Bureau of Harbin under grant No. 2011RFQXG001. J.S.L. acknowledges the financial support provided by the National Natural Science Foundation of China (NSFC) under grant Nos. 51401111 and 51561026, Natural Science Foundation of Inner Mongolia Autonomous Region of China under grant Nos. 2014BS0503, and Scientific Research Foundation of the Higher Education Institutions (SRFHEI) of Inner Mongolia Autonomous Region of China under grant Nos. NJZY14062.

2. Chernenko VA, L'vov V, Pons J and Cesari E. Superelasticity in high-temperature Ni-Mn-Ga alloys. Journal of Applied Physics. 2003; 93(5):2394. http://dx.doi.org/10.1063/1.1539532.

3. Chernenko VA, L'vov VA, Cesari E, Pons J, Rudenko AA, Date $\mathrm{H}$, et al. Stress-strain behaviour of Ni-Mn-Ga alloys: experiment 
and modelling. Materials Science and Engineering A. 2004; 378(1-2):349-352. http://dx.doi.org/10.1016/j.msea.2003.12.052.

4. Qian MF, Zhang XX, Witherspoon C, Sun JF and Müllner P. Superelasticity and shape memory effects in polycrystalline Ni-Mn-Ga microwires. Journal of Alloys and Compounds. 2013; 577(Suppl 1):S296-S299.

5. Brown PJ, Crangle J, Kanomata T, Matsumoto M, Neumann K-U, Ouladdiaf B, et al. The crystal structure and phase transitions of the magnetic shape memory compound Ni2MnGa. Journal of Physics Condensed Matter. 2002; 14(43):10159-10171. http:// dx.doi.org/10.1088/0953-8984/14/43/313.

6. Soto-Parra DE, Alvarado-Hernández F, Flores-Zúñiga H, Moya $\mathrm{X}$, Mañosa L, Planes A, et al. Phase diagram of Fe-doped NiMn-Ga ferromagnetic shape-memory alloys. Physical Review B: Condensed Matter and Materials Physics. 2008; 77(18):184103. http://dx.doi.org/10.1103/PhysRevB.77.184103.

7. Soto-Parra DE, Moya X, Mañosa L, Planes A, Flores-Zúñiga H, Alvarado-Hernández F, et al. Fe and Co selective substitution in $\mathrm{Ni}_{2} \mathrm{MnGa}$ : effect of magnetism on relative phase stability. Philosophical Magazine. 2010; 90(20):2771-2792. http://dx.doi. org/10.1080/14786431003745393.

8. Glavatskyy I, Glavatska N, Dobrinsky A, Hoffmann JU, Söderberg O and Hannula SP. Crystal structure and hightemperature magnetoplasticity in the new Ni-Mn-Ga-Cu. Scripta Materialia. 2007; 56(7):565-568. http://dx.doi.org/10.1016/j. scriptamat.2006.12.019.

9. Roy S, Blackburn E, Valvidares S, Fitzsimmons M, Vogel $\mathrm{S}$, Khan M, et al. Delocalization and hybridization enhance the magnetocaloric effect in $\mathrm{Cu}$-doped $\mathrm{Ni}_{2} \mathrm{MnGa}$. Physical Review B: Condensed Matter and Materials Physics. 2009; 79(23):235127. http://dx.doi.org/10.1103/PhysRevB.79.235127.

10. Li Y, Wang J and Jiang C. Study of Ni-Mn-Ga-Cu as singlephase wide-hysteresis shape memory alloys. Materials Science and Engineering A. 2011; 528(22-23):6907-6911. http://dx.doi. org/10.1016/j.msea.2011.05.060.

11. Cai W, Gao L, Liu AL, Sui JH and Gao ZY. Martensitic transformation and mechanical properties of Ni-Mn-Ga-Y ferromagnetic shape memory alloys. Scripta Materialia. 2007; 57(7):659-662. http://dx.doi.org/10.1016/j.scriptamat.2007.05.041.
12. Gao L, Cai W, Liu AL and Zhao LC. Martensitic transformation and mechanical properties of polycrystalline $\mathrm{Ni}_{50} \mathrm{Mn}_{29} \mathrm{Ga}_{21}{ }_{\mathrm{x}} \mathrm{gd}_{\mathrm{x}}$ ferromagnetic shape memory alloys. Journal of Alloys and Compounds. 2006; 425(1-2):314-317. http://dx.doi.org/10.1016/j. jallcom.2006.01.037.

13 Gao L, Gao ZY, Cai W and Zhao LC. Effect of rare earth Dy addition on microstructure and martensitic transformation of polycrystalline $\mathrm{Ni}_{50} \mathrm{Mn}_{29} \mathrm{Ga}_{21}{ }^{-} \mathrm{Dy}_{\mathrm{x}}$ ferromagnetic shape memory alloys. Materials Science and Engineering: A. 2006; 438-440:1077-1080.

14. Guo S, Zhang Y, Quan B, Li J, Qi Y and Wang X. The effect of doped elements on the martensitic transformation in Ni-Mn-Ga magnetic shape memory alloy. Smart Materials and Structures. 2005; 14(5):S236-S238. http://dx.doi.org/10.1088/09641726/14/5/010.

15. Xin Y, Li Y, Chai L and Xu H. Shape memory characteristics of dual-phase Ni-Mn-Ga based high temperature shape memory alloys. Scripta Materialia. 2007; 57(7):599-601. http://dx.doi. org/10.1016/j.scriptamat.2007.06.010.

16. Chmielus M, Zhang XX, Witherspoon C, Dunand DC and Müllner P. Giant magnetic-field-induced strains in polycrystalline $\mathrm{Ni}$ Mn-Ga foams. Nature Materials. 2009; 8(11):863-866. http:// dx.doi.org/10.1038/nmat2527. PMid:19749769.

17. Chernenko VA, Anton RL, Kohl M, Barandiaran JM, Ohtsuka M, Orue I, et al. Structural and magnetic characterization of martensitic Ni-Mn-Ga thin films deposited on mo foil. Acta Materialia. 2006; 54(20):5461-5467. http://dx.doi.org/10.1016/j. actamat.2006.06.058.

18. Sutou Y, Omori T, Kainuma R, Ishida K and Ono N. Enhancement of superelasticity in $\mathrm{Cu}-\mathrm{Al}-\mathrm{Mn}-\mathrm{Ni}$ shape memory alloys by texture control. Metallurgical and Materials Transactions A. 2002; 33(9):2817-2824. http://dx.doi.org/10.1007/s11661-0020267-2.

19. Guénin G and Gobin PF. A localized soft mode model for the nucleation of thermoelastic martensitic transformation: application to the $\beta \rightarrow 9 \mathrm{R}$ transformation. Metallurgical Transactions $A$. 1982; 13(7):1127-1134. http://dx.doi.org/10.1007/BF02645493. 